\title{
Erratum to: The Correlates between Walkable Environments and Housing Price using Multi-level Model
}

\section{Yeol Choi ${ }^{a}$, Min Jung Seo ${ }^{b}$, and Seung Hwoon $\mathrm{Oh}^{\mathrm{c}}$}

${ }^{a}$ Member, Dept. of Urban Engineering, Pusan National University, Busan 46241, Korea

${ }^{b}$ Dept. of Urban Engineering, HWASEONG Engineering Consultants Co., Ltd., Busan 46243, Korea

${ }^{c}$ Member, Dept. of Urban Planning \& Transportation, Kyonggi University, Suwon 16227, Korea

Erratum to: KSCE Journal of Civil Engineering (2019) 23(10):4516-4524

$10.1007 / \mathrm{s} 12205-019-1894-0$

This erratum is published to notify a correction in the missing dates of the article. See the corrected version below:

Errata:

The original version of this article:

Received/ Revised/ Accepted/ Published Online August 28, 2019

\section{Was altered as:}

Received September 23, 2018/Revised February 14, 2019/Accepted July 15, 2019/Published Online August 28, 2019 